\title{
Influence of static magnetic fields in phototaxis and osmotic stress in Gymnodinium catenatum (Dinophyceae)
}

\author{
Paulo Vale \\ The Portuguese Sea and Atmosphere Institute, I. P. (IPMA, IP), Sea and Marine Resources Department (DMRM), Avenida \\ de Brasília s/n, 1449-006 Lisbon, Portugal
}

\begin{abstract}
Phototaxis response of the toxic microalgae Gymnodinium catenatum was studied in vitro. The percentage of cells remaining at mid-depth $20 \mathrm{~min}$ after stirring increased with solar radio, X-ray and solar flares output. It also increased with geomagnetic activity and temperature, and was dependent on culture time. Increase in the local static magnetic field with a permanent magnet did not influence the positive phototaxis response. However, survival and growth to a provoked hypo-osmotic shock in an altered static magnetic field was dependent on culture time and geomagnetic activity at a threshold below $22 \mathrm{nT}$. The results from phototaxis and hypo-osmotic shock experiments were in line with the previous hypothesis for the existence of two separate deleterious mechanisms conditioning the natural blooms of G. catenatum: one that is dependent on solar radiation and the other that is related to geomagnetic activity. Variations in electromagnetic fields caused by tectonic activity were also capable of influencing G. catenatum phototaxis and growth response in vitro.
\end{abstract}

Key words: Gymnodinium catenatum - Phototaxis - Osmotic stress - Geomagnetic activity Solar cycle - Static magnetic fields - Seismic activity

\section{Introduction}

Harmful algal blooms (HABs) caused by Gymnodinium catenatum Graham at the northwest Atlantic Iberian coast show a large intra-annual variability, but a contrasting more predictable summer to autumnal seasonality (Pazos et al. 2006; Vale et al. 2008; Pitcher et al. 2010). This species is a marine athecate chainforming dinoflagellate producer of paralytic shellfish poisoning toxins (PSTs) (Orr et al. 2013). Its blooms lead to contamination of bivalve molluscs with PSTs, which in turn originate the acute human neurological syndrome, known as PSP (paralytic shellfish poisoning) (FAO 2004).

Electronic supplementary material. The online version of this article (doi: 10.4149/gpb_2016052) contains supplementary material, which is available to authorized users.

Correspondence to: Paulo Vale, Departamento do Mar e Recursos Marinhos (DMRM), Instituto Português do Mar e da Atmosfera, I.P. (IPMA), Avenida de Brasília s/n, 1449-006 Lisbon, Portugal E-mail: pvale@ipma.pt
The decadal-like periodicity in severe PSP episodes attributed to this microalga at the Atlantic Iberian coast can be related to periodical oscillations in solar and geomagnetic activity (S-GMA) (Vale 2013). Analysis of maximal PST's levels accumulated in mussels from the northwest of Portugal between 1986 and 2011 showed accumulation was significantly associated with low levels of solar activity (sunspot number and the solar radio flux, a proxy commonly used for variations in energy output) and also low levels of the aa geomagnetic index (a measure of geomagnetic activity) (Vale 2013). PST's levels derived from G. catenatum in bivalves from the Portuguese south coast were even rarer than at the northwest coast. These were restricted to low aa indexes, but its scarce occurrence did not allow a clear association with solar energy output (Vale 2014).

Cultures of this dinoflagellate were previously subjected to a hypo-osmotic shock and changes in cell concentrations were related to geomagnetic activity (GMA), radio flux (R), X-ray flux and solar X-ray flares (Vale 2017). This hypo-osmotic shock strategy was adopted because electromagnetic fields (EMFs) can alter the activity of ion channels, specifically the voltage-gated calcium channels (Rosen 2003; 
Pall 2013). A strategy that created an ion unbalance was then assessed to enhance effects derived from S-GMA. The increase in cell numbers after periods of 8 or 24 hours was negatively correlated with all of these S-GMA parameters. GMA action was related to the course of the experimental period, while action of electromagnetic radiation (EMR) was significantly related to several hours before the experiments (Vale 2017). The differential action windows might be indicative of two differential disruptive mechanisms: EMR might act on DNA synthesis and mitosis phases of the cell cycle (taking place in the dark period) and GMA might be more disruptive at the end of mitosis or cytokinesis phases taking place in the light period.

Distribution of this microalgae occurs from regions of minimal of the Earth's main magnetic field intensity (Brazil coast: $\sim 23 \mu \mathrm{T}$ ), to intermediate intensity (Morocco-Iberia and Mexican-Pacific coast: $40-45 \mu \mathrm{T})$ and to stronger intensity (Tasmania: $62 \mu \mathrm{T}$ ) (NOAA 2016). However, when the world distribution of G. catenatum (reviewed by Bolch and de Salas 2007) is superposed with the crustal magnetic anomalies determined by aeromagnetic survey, the main coastal locations prefered by this microalga present a negative magnetic anomaly (Vale 2013). These are areas with lower intensity in the local crustal magnetic field, such as Gulf of California, Venezuela, West Iberia, South Tasmania and certain regions of South Australia, Brazil, etc. This static crustal magnetic field originates from locally magnetized rocks in the crust and upper mantle.

The aim of this research was to find in vitro evidence for possible effects resulting from local static magnetic fields when combined with natural variations in S-GMA in this microalga in order to better understand its natural blooms and their relation to the solar cycle and geomagnetic activity. The previous work focused only in growth and chain composition related to S-GMA, in a laboratory environment with minimal alterations of local static magnetic fields (Vale 2017). Another relevant parameter for dinoflagellates is their circadian vertical migration. This physiological trait was here related to both S-GMA and the presence or absence of a strong static magnetic field.

\section{Materials and Methods}

\section{Culturing conditions}

G. catenatum strain $\mathrm{n}^{\circ} \mathrm{IO} .13 .04$ from the algal library of the Instituto de Oceanografia, Lisbon University, was used. It was originally collected offshore from the Espinho coast in September 2005 and isolated from a 2-cell chain.

A bulk culture medium stock was prepared by filtering seawater collected from Cascais Bay on a $20 \mu \mathrm{m}$ sieve. Salinity was measured with a visual hand-held refractometer
(Index Instruments, Ramsey, UK) and adjusted to $35 \mathrm{psu}$ with demineralized water as required, enriched with $f / 2$ nutrients, with extra $10^{-8} \mathrm{M}$ selenium and no silica (f/2+Se medium). The bulk medium was kept refrigerated in the dark. When required, aliquots were sterilized in an oven at $80^{\circ} \mathrm{C}$ for 1 hour, prior to any experiments. Duran ${ }^{\mathrm{R}}$ GL 45 borosilicate bottles were used for maintaining stock cultures and experiments, unless otherwise specified. All bottles were capped with polystyrene Petri-dishes halves, thus allowing light to pass through vertically.

The inoculate for the experiments was maintained in semi-continuous culturing conditions in a $1000 \mathrm{ml}$ bottle (circa $950 \mathrm{ml}$ culture medium). Culture medium was replenished every Friday morning with a 1:1 dilution. Experiments were conducted with cells aged 3-7 days after the media replenishment from the previous week.

For cell counts, unless otherwise specified, triplicate 4-5 $\mathrm{ml}$ sub-samples were taken into 10 - $\mathrm{ml}$ glass tubes, preserved with $45 \mu$ lof Lugol's iodine solution (diluted 1:1 with water) and counted in 96-well micro plates ( $4^{\star} 50 \mu \mathrm{l} /$ sample) using a stereo microscope (model MZ7s, Leica Microsystems, Wetzlar, Germany). The number of cells per chain was recorded in all cases. Homogenization was performed by gentle hand flipping in order to preserve information of chain composition. When the coefficient of variation of triplicate tubes surpassed $15 \%$, the outlier tube was gently homogenized and counted again.

The lighting facility was placed in a cool basement floor without air-conditioning or heating (unless otherwise specified), located at sea-level altitude as described before (Vale 2017). It consisted of overhead vertical illumination with halogen spots providing a 12:12 hour light:dark cycle. Spots supplied halogen light with a 50W-equivalent (Osram, Halopar Eco, 42 W, GU10 type). Distances of spots to the shelf were $57 \mathrm{~cm}$. Photosynthetic active radiation (PAR) was measured at the shelf level with a Li-Cor light meter (Li-Cor, Nebraska, USA). PAR was $43 \mu \mathrm{mol} \mathrm{m}{ }^{-2} \cdot \mathrm{s}^{-1}$ at the centre of the spot focus. Water temperature was measured once daily during the light period.

Lamps were mounted on wood frames attached on top of wooden tables to avoid ferromagnetic material creating static magnetic fields in close proximity to the cultures, thus minimizing distortion of natural magnetic field lines. Indoors artificial electromagnetic fields were kept to a minimum as possible, as described previously (Vale 2017).

\section{Phototaxis experiments}

For measuring vertical migration capability, experiments were carried out in large mouth $350 \mathrm{ml}$ flasks made from ordinary glass. Largemouth flasks were used for allowing simultaneous sampling at two separate locations. A sampling apparatus was constructed by rigidly immobilizing two 1-ml 
syringes in a wood frame (Fig. S1a). Both syringes attained a depth of $4.5 \mathrm{~cm}$ below the water line, for a total water height of $8.5 \mathrm{~cm}$. Long insulin (or tuberculin) syringes without needle were preferred, with an internal length of at least $8 \mathrm{~cm}$.

Cells were homogenized by performing circa 10 times a circular motion with a thin glass rod ( $2 \mathrm{~mm}$ diameter), repeating this operation a few seconds later, and immediately sampled with the apparatus described above. Both aliquots were pooled in a test tube and fixed with $22 \mu \mathrm{l}$ Lugol solution. Flasks were then covered on top with a Petri-dish halve, and laterally with flexible cardboard to block stray light (Fig. S1b). After $20 \mathrm{~min}$, the sampling apparatus was gently lowered and two 1-ml aliquots collected, pooled and fixed as above. Experiments were started between 2 and 3 hours after entering the light phase (9:00-10:00 a.m., the same as UT+0). For studying the influence of natural electromagnetic fields, this phototaxis experiment was run twenty times between late October and late December 2015.

For studying the influence of a localized static magnetic field, a bar magnet was placed below the shelf. A traditional AlNiCo bar magnet with $40 \times 12.5 \times 5 \mathrm{~mm}$ (Silverline, UK) was used. For adjusting the magnet's distance to shelf and 3-D orientation, non-paramagnetic material was used such as plastic and cardboard. The north-seeking pole was placed in an upright position at a distance of $8 \mathrm{~cm}$ from the shelf top, and remained unchanged throughout the experiments. Magnetic fields at the experimental site were measured with a MG-BTA axial hall probe, interfaced with Go! ${ }^{\circledR}$ Link and data acquisition performed by Logger Lite software (Vernier Software \& Technology, Beaverton, USA). The horizontal and vertical components of the field at both shelf levels were presented in Table 1.

Duplicate open mouth flasks were used: one was placed in a shelf without magnet and the other in a shelf with one magnet, both at the center of the spot focus. The center of the shelves were separated by $180 \mathrm{~cm}$, both shelves had the same type of halogen spot and distance to the powerline wires $(\mathrm{cca} 15 \mathrm{~cm})$. For assuring temperature homogenization in the room a heater was placed in the floor with a minimal distance of $120 \mathrm{~cm}$ to the nearest shelf. After placing the heater, alternating magnetic fields in both shelves remained below $<0.01 \mu \mathrm{T}$ (EMFields Professional,
EMFields, UK). This phototaxis experiment was run for ten times in January 2016.

\section{Hypo-osmotic shock experiments}

A 100-ml aliquot was taken and diluted with $35 \mathrm{ml}$ of Milli$\mathrm{Q}$ water, representing a 10 psu salinity drop. This mixture was homogenised and split in two equal portions onto two $100-\mathrm{ml}$ bottles. One bottle was kept in the same shelf as the inoculate and the other was placed in another shelf which had a bar magnet placed below the shelf, as described above. The magnetic alterations introduced were presented in $\mathrm{Ta}$ ble 1. For assuring temperature homogenization in the room a heater was used as described above.

For cell counting triplicate $4-5 \mathrm{ml}$ sub-samples were collected at 0 and 8 hours. Both bottles were left undisturbed between the start and end of the experimental period. Experiments were started between 2 and 3 hours after entering the light phase (9:00-10:00 am). This experiment was carried out along 7 consecutive weeks between February and March 2016. For correlation of chain composition with S-GMA, the pooled data was used, where a total of six replicate tubes were counted each morning: three for the control and another three for the altered magnetic location.

\section{Geomagnetic and seismic activity}

aa Geomagnetic Index values were obtained from International Service of Geomagnetic Indices (http://isgi.unistra. $\mathrm{fr} /$ ). This Index is calculated with data measured at two antipodal magnetic observatories. The an Geomagnetic Index was used before (Vale 2017), but was not available at the time data analysis was performed (due to technical problems with the ISGI servers (http://isgi.unistra.fr/; accessed March 30th 2016)).

The aa Geomagnetic Index is available with a time resolution of 3-hour intervals with a total of eight daily periods, and is expressed in nanoTesla (nT). The first of these periods starts daily from midnight Universal Time (UT), and subsequent periods start at 3, 6, 9, 12, 15, 18 and 21 hours, respectively. Here, these were designated 1 through 8 , respectively.

Table 1. Magnetic field components (in $\mathrm{mT}$ ) at shelf level

\begin{tabular}{lccc}
\hline \multirow{2}{*}{ Location } & & Component & \\
\cline { 2 - 4 } & Horizontal (+north) & Vertical (+down) & Total field (+down) \\
\hline Control (shelf level) & +0.030 & +0.035 & +0.046 \\
Magnet (350 ml flask) & -0.070 to $+0.074^{*}$ & $-0.033^{* *}$ & $-0.018^{* *}$ \\
Magnet (100 ml flask) & -0.077 to $+0.100^{*}$ & $-0.100^{* * *}$ & $-0.067^{* * *}$ \\
\hline
\end{tabular}

${ }^{\star}$ shelf level, from flask south side until north side; ${ }^{* \star}$ at $4.5 \mathrm{~cm}$ above shelf level; ${ }^{* * *}$ at $1.5 \mathrm{~cm}$ above shelf level. Vertical levels and total field chosen correspond to mid of water column in each experiment. 
In the phototaxis experiment, mean daily aa geomagnetic activity was calculated between the $1^{\text {st }}$ and $8^{\text {th }}$ periods of day1. In the osmotic shock experiment, mean daily geomagnetic activity was calculated between the $5^{\text {th }}$ and $8^{\text {th }}$ periods of day- 1 and the $1^{\text {st }}$ and $5^{\text {th }}$ periods of day- 0 .

For chain formation, measured in both experiments early in the morning at T0, mean 24 hour aa geomagnetic activity was calculated from the dawn backwards, covering the $3^{\text {rd }}-8^{\text {th }}$ periods in day- 1 and the $1^{\text {st }}-2^{\text {nd }}$ periods in day- 0 .

Daily records of seismic activity were retrieved from the Portuguese Sea and Atmosphere Institute - IPMA, choosing the 'Continental Portugal and Madeira' area and excluding Azores area (http://www.ipma.pt/pt/geofisica/sismologia/). Only seisms with magnitude above 3.0 on the Richter scale were used. In the phototaxis experiment the total number of seisms was calculated from midnight until 9:00 am. For the hypo-osmotic shock experiments, the total number of seisms from day-2 was used.

\section{Solar activity}

Solar activity parameters were retrieved from NOAA's SWPC Anonymous FTP Server (http://legacy-www.swpc.noaa.gov/ $\mathrm{ftpdir} /$ indices/). Daily values from day-2 were used for data treatment. Solar radio flux $(\mathrm{R})$ is measured in solar flux units $\left(\mathrm{F}_{10.7}\right.$ units), where one unit equals $10^{-22} \mathrm{~W} \cdot \mathrm{m}^{-2} \cdot \mathrm{nm}^{-1}$. Soft X-ray background flux was measured by GOES15 satellite in the 100-800 pm range. Most of X-ray background flux observed during the experimental period corresponded to B-level, or $10^{-7} \mathrm{~W} \cdot \mathrm{m}^{-2}$. Flux in C-level was multiplied by 10 for obtaining the corresponding B-level units. The number of X-ray flares was summed, only $\mathrm{C}$ and $\mathrm{M}$ classes were found during both experimental periods.

\section{Statistical treatment}

Non-linear regressions and $t$-Student test statistics were carried out in SigmaPlot ver. 12.0 (Systat Software, Inc.).

\section{Results}

\section{Phototaxis experiments}

In $\mathrm{f} / 2$ culture medium this strain of Gymnodinium catenatum performs marked daily vertical migrations towards a halogen light source, even in the presence of lateral stray light reflected from the shelf. In the morning, a low density culture $(<1000$ cells $/ \mathrm{ml})$ compacts in the upper few millimeters. Depending on progression of cell density, this compactation will gradually attain $1-2 \mathrm{~cm}$ or more (Fig. S1a). However, this phenomenon cannot be characteristically observed with a fluorescent light source, even when lamps are placed horizontally above the culture flasks (Fig. S2).

The circadian progression of phototaxis was studied along the light phase, with the sampling apparatus described here (Fig. S3a). The minimal concentration of cells at mid-depth was found immediately after entering the light phase ( $<2$ hours) lasting until the $3^{\text {rd }}$ hour. After 8 hours in the light phase, concentration of cells at mid depth increased exponentially. Optimal time window for phototaxis response was then chosen between 2 and up to a maximum of 3 hours after entering the light phase. After being stirred by circular motion with a glass rod, cells rapidly compact towards the surface in about $10 \mathrm{~min}$ (Fig. S3b). An end-point of 20 minutes was then chosen for studying if phototaxis response could be influenced by S-GMA (Fig. S3b).
A

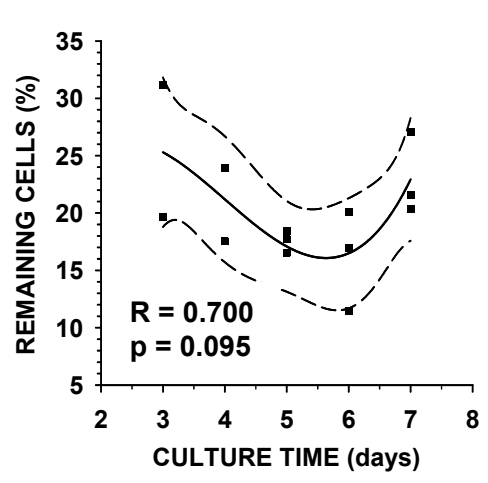

B

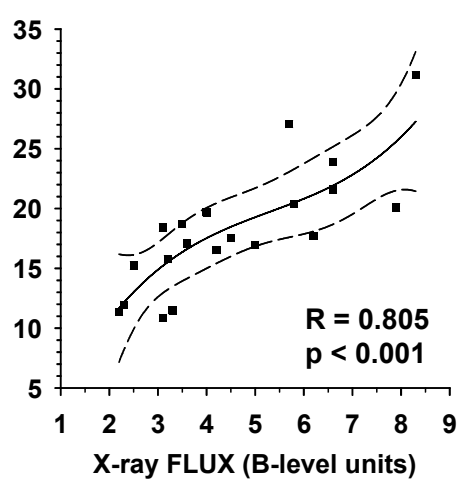

C

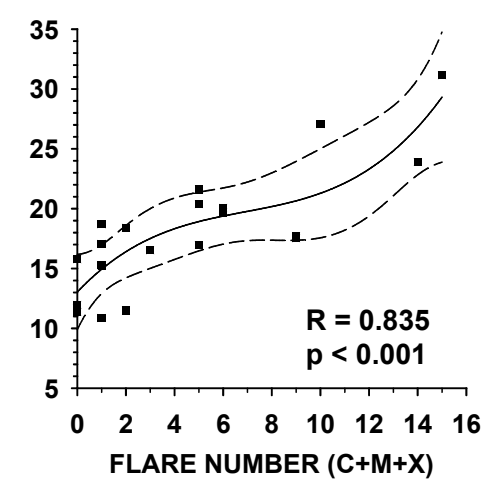

Figure 1. Non-linear regressions for the percentage of $G$. catenatum cells remaining at mid depth after provoked phototaxis and: culture time for X-ray flare number > 1 (A); solar X-ray flux (B); number of solar flares (C). Solid lines represents cubic polynomial fitting and long dashes the $95 \%$ confidence intervals. 
This standardized phototaxis assay was conducted twenty times between November and December 2015. Results were compared with several physiological and physical variables: culture time, initial cell concentration, water temperature, geomagnetic activity, solar radio flux, X-ray flux and X-ray flares. Chain composition in the morning was also correlated with the same parameters in a similar way as before (Vale 2017).

Cell concentration in these experiments varied between 1.7 to $3.6 \times 10^{3}$ cells $/ \mathrm{ml}$. The percentage of cells remaining at mid-depth could not be related with initial cell concentration but was dependent on culture time, with a reduction on days 5 to 6 (Fig. 1A). Dependence on X-ray flux or on the number of X-ray flares could be fitted to a statistically significant third degree polynomial function and presented correlations of 0.805 and 0.835 , respectively, both with $p<0.001$ (Figs. $1 \mathrm{~B}$ and $\mathrm{C}$ ). Correlation was higher if data from days 5 and 6 was selectively removed: $0.91(p<0.01)$.

These experimental results involved multiple measurements from single flaks. The accuracy of these results would be enhanced by performing experiments using multiple measurements from multiple flasks for each exposure condition. To circumvent this shortcoming, and as non-linear regressions did not provide the necessary significance for statistical evaluation of all physical parameters, results were next analysed according to threshold limits set arbitrarily in S-GMA parameters. Below these limits cell concentration at mid-depth was minimal, while above these limits cell concentration was maximal (Fig. 2). The highest significance level was found at a threshold limit of 4.0 X-ray flares/day $(p<0.01)$, followed by X-ray background at $5.5 \mathrm{~B}$-level units, radio flux at $110 \mathrm{~F}_{10.7}$ units, water temperature at $23.5^{\circ} \mathrm{C}$ (all of these at $p<0.01$ ), and geomagnetic activity at $13 \mathrm{nT}$ (at $p<0.05$ ).

Phototaxis experiments were next conducted with cells placed simultaneously at two separate locations, the second location having the local static magnetic field altered by a bar magnet (MAG) but not in the control location (CON). The

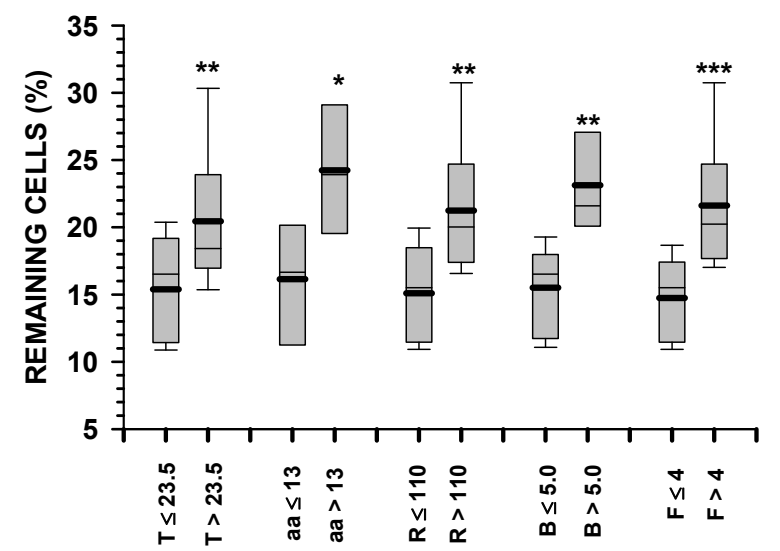

Figure 2. Distribution of cells remaining at mid depth accordingly to threshold limits set at $23.5^{\circ} \mathrm{C}$ in water temperature, $13 \mathrm{nT}$ of aa geomagnetic Index (excepting days 5 and 6), 110 F10.7 units of radio flux (R), 5.0 B-level units X-ray flux (B) or 4 X-ray flares/ day (F). $n=20$, Median, $25 \%$ and $75 \%$ percentiles in grey; $5 \%$ and 95\% percentiles in whiskers; mean in bold; ${ }^{*} p<0.05$; ${ }^{* *} p<0.01$; ${ }^{\star * *} p<0.001$.

MAG location presented the geomagnetic field reverted upwards and total field decreased $0.064 \mathrm{mT}$ at the mid of the water column (Table 1). Experiments were conducted on two consecutive weeks in January 2016, and mean water temperature was $23^{\circ} \mathrm{C}$ at both locations. In January 2016 solar activity was low, and the number of C-flares varied between 0 and $2 /$ day. In the first week cell concentration begun at $1.8 \times 10^{3}$ cells $/ \mathrm{ml}$, while in the second week it begun at $1.0 \times 10^{3}$ cells $/ \mathrm{ml}$. In the first week a mean of $10.6 \%$ and $11.2 \%$ of cells remained at mid depth in the CON and MAG locations, respectively (Fig. 3A). The difference between both locations was not statistically significant. In the second week a mean of $20.8 \%$ and $27.7 \%$ of cells remained at mid depth in the CON and MAG locations, respectively, but difference between both locations was not statistically significant (Fig. 3A).
A
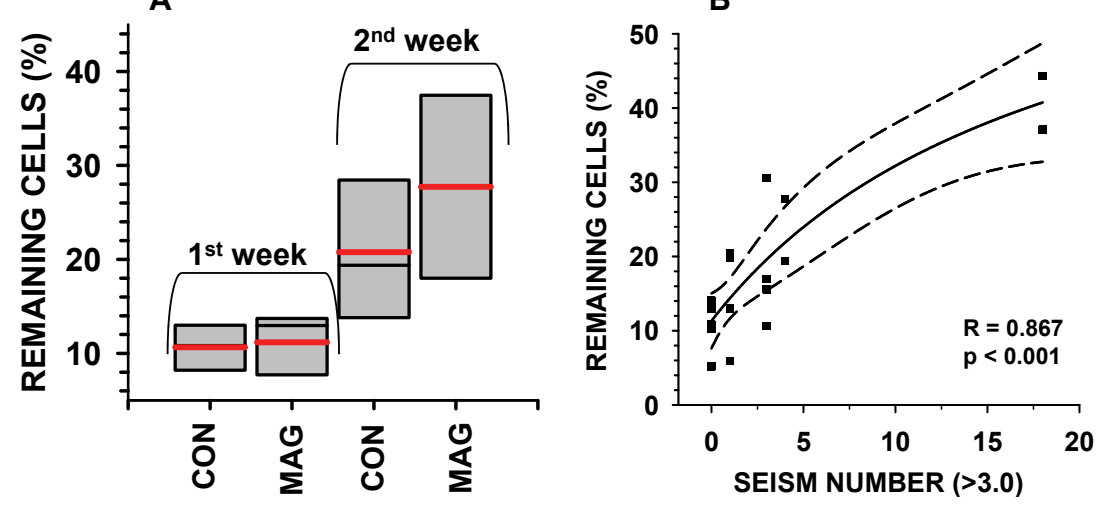

Figure 3. A. Distribution of cells remaining at mid depth in the absence (CON) or presence (MAG) of a magnet in two consecutive weeks. Median, 25\% and $75 \%$ percentiles in grey; mean in bold. B. Correlation of pooled data from same experiment with the number of seisms with magnitude above 3.0 on the Richter scale that occurred during the 12 hours prior to the experiment. Solid line represents hyperbolic fitting and long dashes the $95 \%$ confidence intervals. 
During the second week, initial cell concentrations were lower but solar activity was higher with 4 out of 5 days with 1-2 C-class flares/day (contrasting to 4 out of 5 days with $0 \mathrm{C}$-class flares/day in the previous week). With a higher number of X-ray flares it was expectable the phototaxis response decreased, with a concomitant increase in cells at mid-depth. However, an unexpectedly high percentage of cells were found at mid depth in one of these days at both locations (around $40 \%$ on Monday, day 3 ). This result draw attention to the possibility of an external influence derived from another type of physical variable: electromagnetic phenomena preceding and accompanying seismic events. On the night before this result was obtained, a notorious 5.6 Earthquake on the Richter scale occurred further south at the Alboran Sea, causing material damage in the south of Spain and north of Morocco. Seismic activity was recurrent along that day and subsequent days, altering drastically average seismic activity at the boundary between the African and Eurasian plates for the entire month of January (Fig. S4a). The number of seisms with magnitude above 3.0, which occurred in the preceding 9 hours, was correlated with the phototaxis response: in both CON and MAG locations, response decreased with the increase in seismic activity (Fig. S4b). The pooled data was presented in Fig. 3B: it followed an exponential rise to maximum non-linear regression.

Chain composition of cells remaining at mid-depth was not representative of the original undisturbed population prior to stirring. As chain composition varies with temperature (Vale 2017), only data from the second set of phototaxis experiments, where temperature remained constant around $23^{\circ} \mathrm{C}$, was used here for analysis. Pooled

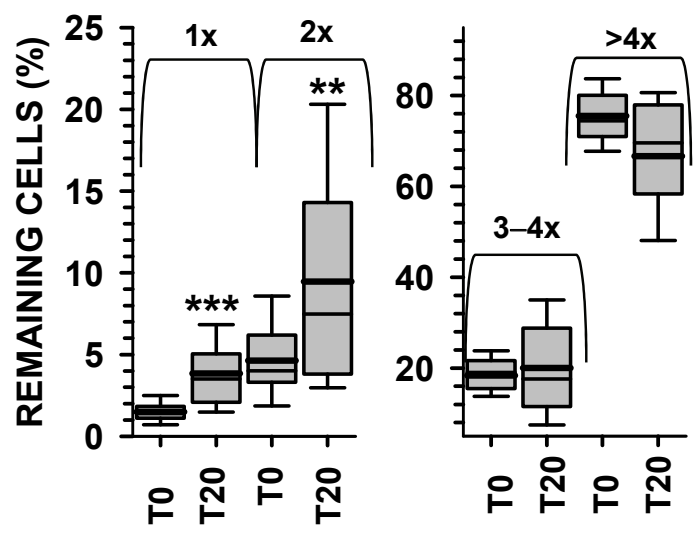

Figure 4. Distribution of cells by chain length: singlets (1x), doublets ( $2 \mathrm{x}), 3-4$ cells $(3-4 \mathrm{x})$ or $>4$ cells/chain $(>4 \mathrm{x})$ in the population at $0 \mathrm{~min}$ (T0) and remaining at mid-depth $20 \mathrm{~min}$ after provoked phototaxis (T20). Pooled data are with and without a magnet. Median, $5 \%$ and $95 \%$ percentiles, mean in bold line. Statistically significant differences at: ${ }^{* *} p<0.01 ;{ }^{* *} p<0.001$. data from phototaxis in the absence or presence of a magnet were used. The percentage of cells in singlets and 2-cell chains remaining at mid-depth almost doubled after 20 min: from 1.5 to $3.8 \%$ and from 4.6 to $9.5 \%$, respectively (Fig. 4). Both alterations were statistically significant, with $p<0.001$ and $p<0.01$, respectively. In the longer chain formations (i.e. $>4$ cells/chain) the population reduced from 75.5 to $66.7 \%$ (Fig. 4).

\section{Osmotic shock experiments}

The osmotic shock response was studied previously and could be related to variations in S-GMA parameters (Vale 2017). Since the design of the experimental facility used here, ferromagnetic materials were carefully avoided in order to not introduce local alterations to the Earth's geomagnetic field. A pilot trial was conducted by placing a bar magnet in several 3-D positions below the culture shelf (MAG location). At the end of the experimental period, final cell concentrations differed from the control (CON location). No apparent relation could be established with the magnet orientation, but a relation emerged with geomagnetic activity and culture time (data not shown).

A single vertical position with the north-seeking pole upward was chosen, in order to simplify the numerous possibilities to test. In all cases, magnetic field vectors are not only aligned with the magnet longer axis, but vectors of weaker intensity occur in numerous other directions, as typical from a classic dipole magnet, that presents curved magnetic field lines. The MAG location presented the geomagnetic field reverted upwards and total field decreased $0.113 \mathrm{mT}$ at the mid of the water column (Table 1).

Hypo-osmotic assays were conducted between February and March 2016, comprising 7 consecutive weeks and a total of 33 repetitions. At the end of the 8-hour experimental period cell concentrations were compared to initial concentrations on a percentage basis in both the $\mathrm{CON}$ and MAG locations. The difference between the MAG and the CON relative concentrations was plotted against several physiological and physical variables: culture time, initial cell concentration, water temperature, geomagnetic activity, solar radio flux, X-ray flux, X-ray flares and seismic activity. Chain composition at T0 was also correlated with the same parameters in a similar fashion.

Cell concentration varied between 1.1 to $2.0 \times 10^{3}$ cells $/ \mathrm{ml}$ and temperature was kept within 22 and $23^{\circ} \mathrm{C}$. Differences in G. catenatum grown in the MAG location when compared to the control (CON location) could not be related with initial cell concentration, temperature, radio flux, X-ray flux and number of flares (data not shown), but it was dependent on culture time and seismic activity (Fig. 5).

Difference between the MAG and CON locations decreased progressively with culture time, following a third 


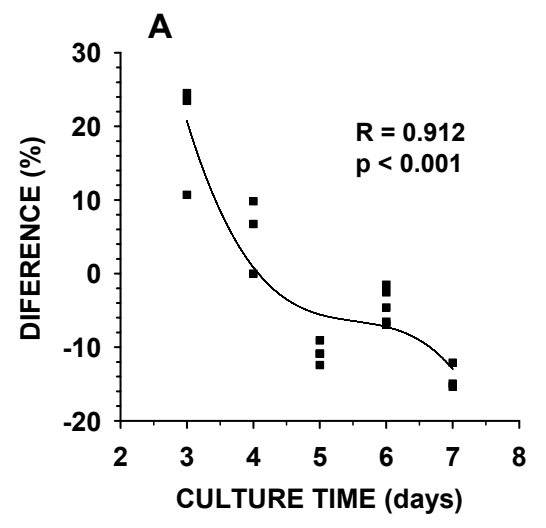

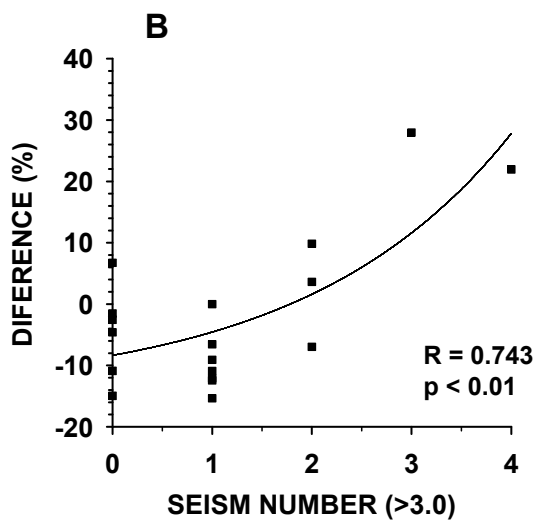

Figure 5. Non-linear regressions for differences in cell concentration when exposed to a static magnetic field versus control against: culture time, for aa geomagnetic index $\leq 22 \mathrm{nT}$ and seism number $<3(n=18 ; \mathbf{A})$; daily number of seisms with magnitude $>3.0$, for culture time $>3$ days and aa geomagnetic index $\leq 26 \mathrm{nT}(n=18 ; \mathbf{B})$. degree polynomial curve. Growth was higher in the MAG location on days 3 and 4 but was lower between days 5 and 7 (Fig. 5A). Differences found at begin of each week were mainly attributed to the negative growth obtained in the CON location, but not in the MAG location (Figs. S5a and b). This temporal difference did not hold true for days with aa geomagnetic Index above $22 \mathrm{nT}$ : the mean differences were -1.5 and +0.5 , respectively for days 3 to 4 and 5 to 7 , but were not statistically significant (Fig. 6). These differences were statistically significant for $\mathbf{a a} \leq 22$ nT between days 3-4 and days 5 to 7 , and also for days 5 to 7 between $\mathbf{a a} \leq 22 \mathrm{nT}$ and $\mathbf{a a}>22 \mathrm{nT}$ (Fig. 6).

G. catenatum growth was higher in the MAG location when the daily number of seisms with magnitude above 3.0 surpassed 1 per day (Fig. 5B). In all the trials, when seism number was above 1 day, growth was negative in the CON location (Figs. S5c and d).

The correlation of chain composition with physical parameters has been done already by Vale $(2015,2017)$. It was found salinity and temperature were important factors: the proportion of cells in long chain formation (equal or greater than 4 cells/chain) reduced at higher salinities and temperatures. In the present research temperature was kept with minimal variations: only within $1^{\circ} \mathrm{C}$, when compared with the data reported in Vale (2017) which varied between 3 and $3.5^{\circ} \mathrm{C}$. This was a good opportunity to reassess the relation of chain formation with S-GMA parameters.

Cells in long chain formation accounted for a mean 57\% of the cells. However this ratio was dependent on S-GMA. On days 3 and days 6-7 it increased up to $70 \%$ when X-ray flux was above 2.0 B-level units or Radio flux above $100 \mathrm{~F}_{10.7}$ units (Figs. 7A and B). A different correlation was observed for the highest levels of geomagnetic activity (above $26 \mathrm{nT}$ ): chain formation attained minimal levels on day 3 (around $32 \%$ ), increasing progressively with culture time up to $60 \%$ (Fig. 7C). No correlation could be established with flare or seism number (Fig. 8).

\section{Discussion}

Experiments were carried out in late 2015 and early 2016, during the declining phase from the maximum of solar cycle number 24 (NASA 2016, http://solarscience.msfc.nasa. gov/SunspotCycle.shtml; accessed March 30th 2016). At this stage of the cycle, solar activity is declining and wide variations in sunspot area, solar radio flux, X-ray flares and coronal mass ejections (CME) were not so easily obtained along each experimental period as during the previous research carried out in early and mid 2015 (Vale 2017).

The positive phototaxis phenomena described here cannot be distinctly observed in G. catenatum cultures when a fluorescent light source is used, even when the lamps are placed above the culture flasks and opaque shelves are used (Fig. S2). In some types of culture cabinets lamps are placed laterally

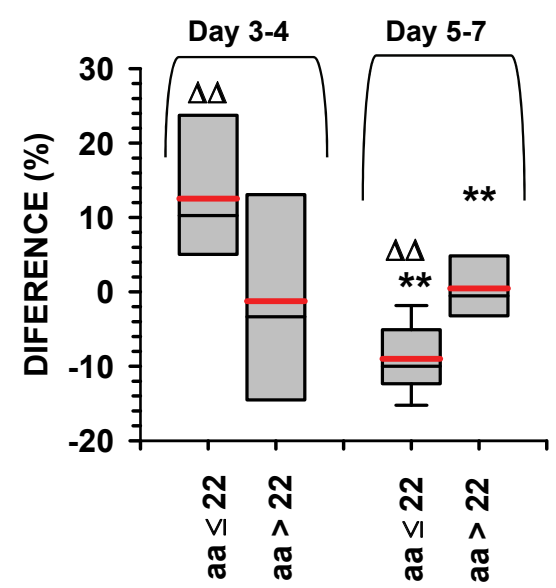

Figure 6. Distribution of differences in cell concentration when exposed to a static magnetic field versus control accordingly to threshold limits set at $22 \mathrm{nT}$ in aa geomagnetic activity during days 3 and 4 or days 5 through 7 . Median, 25\% and 75\% percentiles in grey; $5 \%$ and $95 \%$ percentiles in whiskers; mean in bold; $\Delta \Delta, * * p<0.01$. 
A

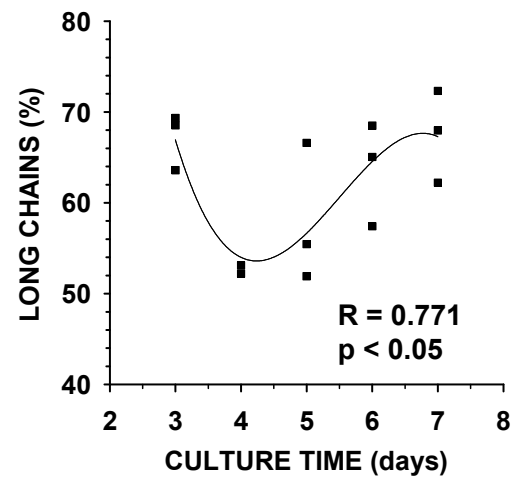

B

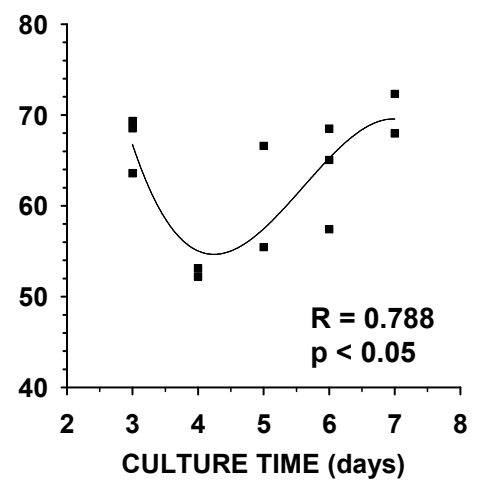

C

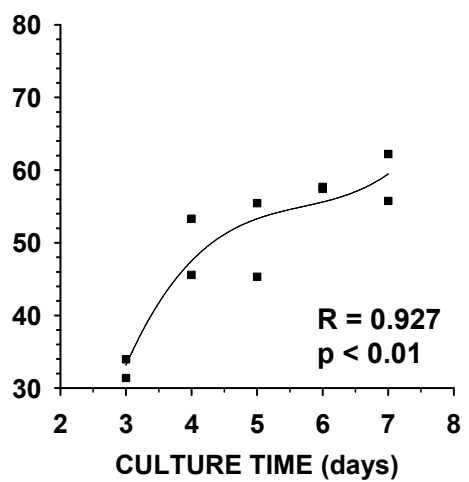

Figure 7. Percentage of cells in long chain formation versus X-ray flux > 2.0 B-level units (A); radio flux > 100 F10.7 units (B); aa geomagnetic index $>26 \mathrm{nT}(\mathbf{C})$. The lines represent third-degree polynomial regressions.

or even glass shelves are used, causing light to penetrate the flaks both laterally and underneath. These models are also available at our Institution, and a marked positive phototaxis response also cannot be observed in this case. The positive phototaxis was not altered in the vicinity of a bar magnet, even with the field reversed (Table 1), as can occur with some magnetotatic protists (Bazylinski et al. 2000).

The negative phototaxis observed when transferred from halogen to fluorescent light (unpublished observations) can be attributed to its high photosensitivity towards near-UVA/ violet light (Vale 2015). Fluorescent sources possess narrow, but extremely intense, UVA and violet light bands derived from the mercury lines at $365 \mathrm{~nm}$ and at $405 \mathrm{~nm}$, respec-

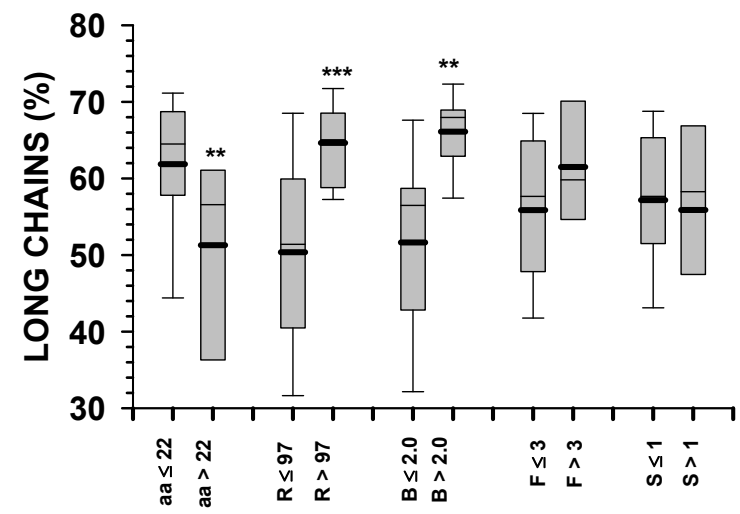

Figure 8. Percentage of cells in long chain formation, excluding culture time 4-5 days, and according to threshold limits set at $22 \mathrm{nT}$ of aa geomagnetic Index, at 97 F10.7 units of radio flux (R), at 2.0 B-level units X-ray flux (B), at $3 \mathrm{X}$-ray flares/day (F) or at 1 seism/day with magnitude above 3.0 (S). Median, $25 \%$ and $75 \%$ percentiles in grey; $5 \%$ and $95 \%$ percentiles in whiskers; mean in bold. ${ }^{\star *} p<0.01 ;{ }^{* * *} p<0.001$. tively. When grown under halogen light there is a minor accumulation of M-370, the major UVA photo-protective mycosporine-like amino acid (MAA) (Vale 2015). But even after acclimation to fluorescent light, accompanied by an increase in M-370 levels, a marked positive phototaxis response is still lacking (unpublished observations).

Results from previous growth experiments led to suspect that not only UV radiation could be detrimental, but also increase in S-GMA could negatively influence its growth, even indoors (Vale 2017). In the present research, phototaxis response in G. catenatum was approached for the first time to understand if it could be influenced by S-GMA. Fluctuations in S-GMA parameters did not influence the general positive phototaxis response in G. catenatum but could influence the speed for that response. The strongest correlations for provoked phototaxis were found for fluctuations in X-ray radiation and $\mathrm{X}$-ray flares, but correlations were weaker for geomagnetic activity or temperature. These correlations were found for the increase in radiation more than 24 hours before the experiment. These results strength our previous hypothesis that background X-ray radiation could cause cellular damage probably DNA lesions - that require time to repair (Vale 2017).

Impaired genomics will negatively influence proteomics, with detrimental outcomes for any cell. In the case of the flagella required for swimming, at least 360 proteins have been identified with high confidence and another 292 as candidate flagellar proteins in the green alga Chlamydomonas reinhardtii (Pazour et al. 2005). These are motor proteins, signal transduction proteins, glycolytic enzymes, amongst other uncharacterized of proteins. Genes encoding for proteins require not only their own structural integrity, but their translation is also dependent on other genes that regulate their translation: the regulatory genes (Winck et al. 2013).

The impairment in the phototaxis response could also result from altered cryptochrome regulation. Activation of 
this flavoprotein, which regulates growth and development in plants, will interact with downstream receptors to transfer the photo and magnetic signals (Wang et al. 2015). Cryptochrome regulation is dependent on radical pair reactions (Solov'yov and Schulten 2009). Alteration in the normal metabolic production of reactive oxygen species (ROS) can be influenced by extremely high frequency radiation, such as X-rays, (Mikkelsen and Wardman 2003), but also extremely low frequency (ELF) magnetic fields exert their effects by enhancing the activity or lengthening the lifetime of radical pairs (Scaiano et al. 1994; Timmel et al. 1998).

Existence in chain formation can enhance motility (Fraga et al. 1989; Smayda 2002), enabling dinoflagellates to resist vertical mixing and convective dispersion, which are potentially detrimental to cellular or population growth. Increased motility also facilitates diel and nutrient-gathering migrations (Smayda 2002). Using a video camera and VCR recording Fraga et al. (1989) observed that velocity increased 1.5-1.6-fold in Gymnodinium catenatum and Alexandrium affine for 8-cell chains in comparison to solitary cells. Using modern digital holographic particle tracking velocimetry (PTV) technique, Sohn et al. (2011) found a 2.2-fold increase in 8-cell chains in comparison to solitary cells of Cochlodinium polykrikoides (a dinoflagellate of similar size).

The results obtained here were also in accordance with observations from these authors, where solitary cells and duplets had less motility after provoked phototaxis, while quartets could not be distinguished from octets, as also observed for example by Sohn et al. (2011). However, the length of chains increases with S-GMA, and this does not necessarily translates into a generalized faster response from the population (Figs. 1, 2, 7 and 8). It was previously observed that the length of chains can both indicate a healthy population, but in some cases can probably result from any impairment in cell division (Vale 2015, 2017). The discussion above regarding flagellar assembly and motility, relates also to the cytoskeleton in general, which has many shared proteins such as tubulin, actin, dyneins, etc. (Pazour et al. 2005). Impaired cell division can certainly be related to cytoskeleton anomalies, amongst anomalies in other organelles, but this level of detail was outside the scope of this experimental approach.

The experimental design used here aimed at maintaining cells continually in mid-exponential phase, by replenishing media in small portions at a time (approximately in a 1:1 proportion) every week. Nevertheless, in both the phototaxis and the osmotic shock experiments the results were distinctly related with the time spent after media replenishment (Figs. $1 \mathrm{~A}$ and $5 \mathrm{~A}$ ). When observing the average evolution of the relative cell concentrations in the inoculate (as measured at T0) and culture time, a small growth disacceleration was observed between days 3 and 5, followed by small growth acceleration after day 5 (Fig. S6).
When studying the behaviour of mycosporine-like aminoacids in G. catenatum, it was confirmed that these compounds could have multiple roles: UV light protectors, anti-oxidants and osmolytes (Vale 2016). When cells were transferred to fresh media, most of the MAAs increased up to day 2 or 3 and then declined. Only past one week these trend reverted and cellular concentration of these metabolites increased again (Vale 2015).

In the case of the phototaxis experiment, cells were more active on days 5-6, corresponding to lower concentrations at mid-depth (Fig. 1A). These corresponded to X-rays acting on days 3-4 respectively, which is coincidental when MAAs with an anti-oxidant role attained maximal levels (Vale 2015, 2016). In the case of the hypo-osmotic shock experiment, cells without an altered local static magnetic field were more sensitive on day 3 (Fig. S5a). MAAs with a putative osmolyte role increased sharply mainly until day 2, and then declined (Vale 2015). A drastic reduction in osmolarity of culture media would force loss of molecules with an osmolyte role, disrupting cellular homeostasis at a critical time. This loss was already confirmed for certain MAAs, such as porphyra-334 and shinorine (Vale 2016).

The activity of ion channels can be altered by electromagnetic fields, specifically the voltage-gated calcium channels, and to a lesser extent the sodium channels (Rosen 2003; Pall 2013). As early as 1985, both Blackman et al. (1985) and Liboff (1985) observed dependence between the frequency of the variable field and the magnitude of the static geomagnetic field. An example of this kind is the bioluminescence of the dinoflagellate, Gonyaulax scrippsae, which is affected by a combination of static and ELF magnetic fields in the microTesla range (Berden et al. 2001).

In this line of reasoning, altering the static magnetic field protected cells from the hypo-osmotic shock on days 3-4, but the reverse effect was found on days 5-7 (Fig. 5A). In G. catenatum accented time-dependent alterations in osmolyte content have been observed in the first days immediately after culture media replenishment (Vale 2015, 2016). These changes in osmolyte content, among other physiological parameters not measured so far, will certainly alter the optimal combination of static and variable magnetic fields in which this species grows best.

Seismo-electromagnetic (SEM) phenomena from earthquakes and volcanic eruptions have been reported for sometime (Park et al. 1993). SEM phenomena include the changes of the following observations: the earth resistivity, the geoelectric field, the geomagnetic field, the electromagnetic emissions at various frequencies, and the secondary electromagnetic phenomena (e.g., the disturbance of the ionosphere) (Huang and Liu 2006).

The understanding of the generation and propagation of electromagnetic earthquake precursors is still incomplete due to the difficulty in how to scale up laboratory results to 
the enormous and heterogeneous rock volumes involved in the preparation of large earthquakes (Vallianatos et al. 2004). Electromagnetic phenomena preceding and accompanying seismic events attracts attention in some countries as possible earthquake precursors and also as additional parameters for describing the Earth's crust and its dynamics (Gershenzon and Bambakidis 2001). Observation of SEM effects in the wildlife has been mainly restricted to animal behaviour and could explain how terrestrial or aquatic animals apparently can sense impending earthquakes weeks in advance (Bhargava et al. 2009; Freund and Stolc 2013). Contrasting with terrestrial animals, aquatic animals such as sharks, rays, and some fish often have greater electrical sensitivity due to specialized organs used for both communication and prey location (Bullock 1982).

The hypothesis that SEM activity could restrict G. catenatum blooms was placed before (Vale 2014). This was done because blooms in the south of Portugal are much rarer than in the north coastline. The south coastline is located near the boundary between the African and Eurasian plates, which is constantly marked by moderate seismicity. But no definitive conclusions could be drawn. This could have resulted from the large time-window used for observation (1 month in time-span).

Inclusion of SEM activity was not done in the previous search for effects derived from S-GMA in cultures (Vale 2017), because events of large magnitude are very rare indeed. For example, during 2015 seisms with magnitude above 3.0 on the Richter scale occurred with an average of 4 per month (or circa 1 per week) (Fig. S4a). However, in January 2016 it increased to 50 per month and continued above average ( $>20$ per month) in February and March (Fig. S4a). The influence of SEM in G. catenatum cultures was minimized by a strong local static magnetic field when subjected to an instantaneous hypo-osmotic stress (Fig. 5 and S5), but not in the case of the phototaxis response (Fig. S3b).

In summary, the results from the phototaxis and hypoosmotic shock experiments obtained here were in agreement with both the previous theoretical approach (Vale 2013,2014 ) and the recent in vitro experiments (Vale 2017), that put forward a hypothesis for the existence of two separate deleterious mechanisms conditioning the natural blooms of G. catenatum. One mechanism is dependent on solar radiation and the other one is related to geomagnetic activity (Vale 2013). Solar radiation in the X-ray range can affect genomics by generation of reactive oxygen species (reviewed in Breen and Murphy 1995), while electromagnetic fields can alter activity of ion channels, specifically the voltage-gated calcium channels (Rosen 2003; Galland and Pazur 2005; Pall 2013). The terrestrial influence seems more complicated than previously thought, because variations in electromagnetic fields caused by tectonic activity also seem capable of influencing G. catenatum physiology. In order to understand these external influences, cell condition is essential, and acclimatation to fresh culture media cannot be disregarded.

Acknowledgements. The results presented in this paper rely on geomagnetic indices calculated and made available by ISGI Collaborating Institutes from data collected at magnetic observatories. We thank the involved national institutes, the INTERMAGNET network and ISGI (isgi.unistra.fr). Appreciation is due to NOAA's Space Weather Prediction Center, USA, for usage of solar data, and IPMA's Geophysics Division for usage of seismic data. Funding for IPMA was obtained from PROMAR (EU 2007-2013 Operational Fisheries Program). M.M. Angélico provided access to the stereo microscope.

\section{References}

Bazylinski D. A., Schlezinger D. R., Howes B. H., Frankel R. B., Epstein S. S. (2000): Occurrence and distribution of diverse populations of magnetic protists in a chemically stratified coastal salt pond. Chem. Geol. 169, 319-328

https://doi.org/10.1016/S0009-2541(00)00211-4

Berden M., Zrimec A., Jerman I. (2001): New biological detection system for weak ELF magnetic fields and testing of the paramagnetic resonance model (Lednev 1991). Electro. Magnetobiol. 20, 27-41 https://doi.org/10.1081/JBC-100103158

Bhargava N., Katiyar V. K., Sharma M. L., Pradhan P. (2009): Earthquake prediction through animal behavior: a review. Indian Journal of Biomechanics: Special Issue, 159-165

Blackman C. F., Benane S. G., Rabinowitz J., House D. E., Joines W. (1985): A role of the magnetic field in the radiation induced efflux of calcium ions from brain tissue in vitro. Bioelectromagnetics 6, 327-337 https://doi.org/10.1002/bem.2250060402

Bolch C. J. S., de Salas M. F. (2007): A review of the molecular evidence for ballast water introduction of the toxic dinoflagellates Gymnodinium catenatum and the Alexandrium „tamarensis complex" to Australasia. Harmful Algae 6, 465-485 https://doi.org/10.1016/j.hal.2006.12.008

Breen A. P., Murphy J. A. (1995): Reactions of oxyradicals with DNA. Free Radic. Biol. Med. 18, 1033-1077

https://doi.org/10.1016/0891-5849(94)00209-3

Bullock T. H. (1982): Electroreception. Annu. Rev. Neurosci. 5, $121-170$

https://doi.org/10.1146/annurev.ne.05.030182.001005

FAO (2004): Marine Biotoxins, FAO Food and Nutrition Paper, 80. Food and Agriculture Organization of the United Nations, Rome. 278 pp.

Fraga S., Gallacher S. M., Anderson D. M. (1989): Chain-forming dinoflagellates: an adaptation to Red-Tides. In: Red Tides: Biology, Environmental Science, and Toxicology. Proceedings of the First International Symposium on Red Tides. (Eds. T. Okaichi, D. M. Anderson, T. Nemoto), pp. 281-284, Elsevier, New York 
Freund F., Stolc V. (2013): Nature of pre-earthquake phenomena and their effects on living organisms. Animals 3, 513-531 https://doi.org/10.3390/ani3020513

Galland P., Pazur A. (2005): Magnetoreception in plants. J. Plant. Res. 118, 371-389 https://doi.org/10.1007/s10265-005-0246-y

Gershenzon N., Bambakidis G. (2001): Modeling of seismoelectromagnetic phenomena. Russian Journal of Earth Sciences 3, 247-275 https://doi.org/10.2205/2001ES000058

Huang Q.-H., Liu T. (2006): Earthquakes and tide response of geoelectric potential field at the Niijima station. Chinese. J. Geophys. 49, 1585-1594 https://doi.org/10.1002/cjg2.986

Liboff A. R. (1985): Geomagnetic cyclotron resonance in living cells. Biol. Phys. 9, 99-102 https://doi.org/10.1007/BF01878387

Mikkelsen R. B., Wardman P. (2003): Biological chemistry of reactive oxygen and nitrogen and radiation-induced signal transduction mechanisms. Oncogene 22, 5734-5754 https://doi.org/10.1038/sj.onc.1206663

Orr R. J. S., Stüken A., Murray S. A., Kjetill J. S. (2013): Evolution and distribution of saxitoxin biosynthesis in dinoflagellates. Mar. Drugs 11, 2814-2828 https://doi.org/10.3390/md11082814

Pall M. L. (2013): Electromagnetic fields act via activation of voltage-gated calcium channels to produce beneficial or adverse effects. J. Cell. Mol. Med. 17, 958-965 https://doi.org/10.1111/jcmm.12088

Park S. K., Johnston M. J. S., Madden T. R., Morgan F. D., Morrison H. F. (1993): Electromagnetic precursors to earthquakes in the ULF band: a review of observations and mechanisms. Rev. Geophys. 31, 117-132 https://doi.org/10.1029/93RG00820

Pazos Y., Moro-o A., Tri-anes J., Doval M., Montero P., Vilarinho M. G., Moita M. T. (2006): Early detection and intensive monitoring during an anusual toxic bloom of Gymnodinium catenatum advected into the Galician Rías (NW Spain). In: 12th International Conference on Harmful Algae, Programme and Abstracts, Copenhagen, Denmark, p. 259

Pazour G. J., Agrin N., Leszyk J., Witman G. B. (2005): Proteomic analysis of a eukaryotic cilium. J. Cell Biol. 170, 103-113 https://doi.org/10.1083/jcb.200504008

Pitcher G. C., Figueiras F. G., Hickey B. M., Moita M. T. (2010): The physical oceanography of upwelling systems and the development of harmful algal blooms. Prog. Oceanogr. 85, 5-32 https://doi.org/10.1016/j.pocean.2010.02.002

Rosen A. D. (2003): Mechanism of action of moderate-intensity static magnetic fields on biological systems. Cell Biochem. Biophys. 39, 163-174 https://doi.org/10.1385/CBB:39:2:163

Scaiano J. C., Cozens F. L., McLean J. (1994): Model for the rationalization of magnetic field effects in vivo. Application of the radical-pair mechanism to biological systems. Photochem. Photobiol. 59, 585-589

Smayda T. J. (2002): Turbulence, watermass stratification, and harmful algal blooms: an alternative view and frontal zones as ,Pelagic Seed Banks“. Harmful Algae 1, 95-112
https://doi.org/10.1016/S1568-9883(02)00010-0

Sohn M. H., Seo K. W., ChoiY. S., Lee S. J., Kang Y. S., Kang Y. S. (2011): Determination of the swimming trajectory and speed of chainforming dinoflagellate Cochlodinium polykrikoides with digital holographic particle tracking velocimetry. Mar. Biol. 158, 561-570

https://doi.org/10.1007/s00227-010-1581-7

Solov'yov I. A., Schulten K. (2009): Magnetoreception through cryptochrome may involve superoxide. Biophys. J. 96, 4804-4813 https://doi.org/10.1016/j.bpj.2009.03.048

Timmel C. R., Till U., Brocklehurst B., Mclauchlan K. A., Hore P. J. (1998): Effects of weak magnetic fields on free radical recombination reactions. Mol. Phys. 95, 71-89 https://doi.org/10.1080/00268979809483134

Vale P. (2013): Can solar/geomagnetic activity restrict the occurrence of some shellfish poisoning outbreaks? The example of PSP caused by Gymnodinium catenatum at the Atlantic Portuguese coast. Biophysics 58, 554-567 https://doi.org/10.1134/S0006350913040179

Vale P. (2014): Modeling the occurrence of shellfish poisoning outbreaks caused by Gymnodinium catenatum (Dinophyceae) through electromagnetic signal triggering. Biophysics $59,464-474$ https://doi.org/10.1134/S0006350914030257

Vale P. (2015): Effects of light and salinity stresses in production of mycosporine-like amino acids by Gymnodinium catenatum (Dinophyceae). Photochem. Photobiol. 91, 1112-1122 https://doi.org/10.1111/php.12488

Vale P. (2016): Can mycosporine-like amino acids act as multifunctional compounds in Gymnodinium catenatum (Dinophyceae)? Photochem. Photobiol. 92, 264-275 https://doi.org/10.1111/php.12561

Vale P. (2017): Influence of solar and geomagnetic activity in Gymnodinium catenatum (Dinophyceae) cultures. Gen. Physiol. Biophys. 36, 7-21

Vale P., Botelho M. J., Rodrigues S. M., Gomes S. S., Sampayo M. A. M. (2008): Two decades of marine biotoxin monitoring in bivalves from Portugal (1986-2006): a review of exposure assessment. Harmful Algae 7, 11-25 https://doi.org/10.1016/j.hal.2007.05.002

Vallianatos F., Triantis D., Tzanis A., Anastasiadis C., Stavrakas I. (2004): Electric earthquake precursors: from laboratory results to field observations. Phys. Chem. Earth. 29, 339-351 https://doi.org/10.1016/j.pce.2003.12.003

Wang J., Du X., Pan W., Wang X., Wu W. (2015): Photoactivation of the cryptochrome/photolyase superfamily. J. Photoch. Photobiol. C 22, 84-102

Winck F. V., Arvidsson S., Ria-o-Pachón D. M., Hempel S., Koseska A., Nikoloski Z., Gomez D. A. U., Rupprecht J., Mueller-Roeber B. (2013): Genome-wide identification of regulatory elements and reconstruction of gene regulatory networks of the green alga Chlamydomonas reinhardtii under carbon deprivation. PLoS ONE 8, e79909 https://doi.org/10.1371/journal.pone.0079909

Received: July 20, 2016

Final version accepted: October 20, 2016

First published online: May 4, 2017 


\section{Influence of static magnetic fields in phototaxis and osmotic stress in Gymnodinium catenatum (Dinophyceae)}

\section{Paulo Vale}

The Portuguese Sea and Atmosphere Institute, I. P. (IPMA, IP), Sea and Marine Resources Department (DMRM), Avenida de Brasília s/n, 1449-006 Lisbon, Portugal

a)

b)
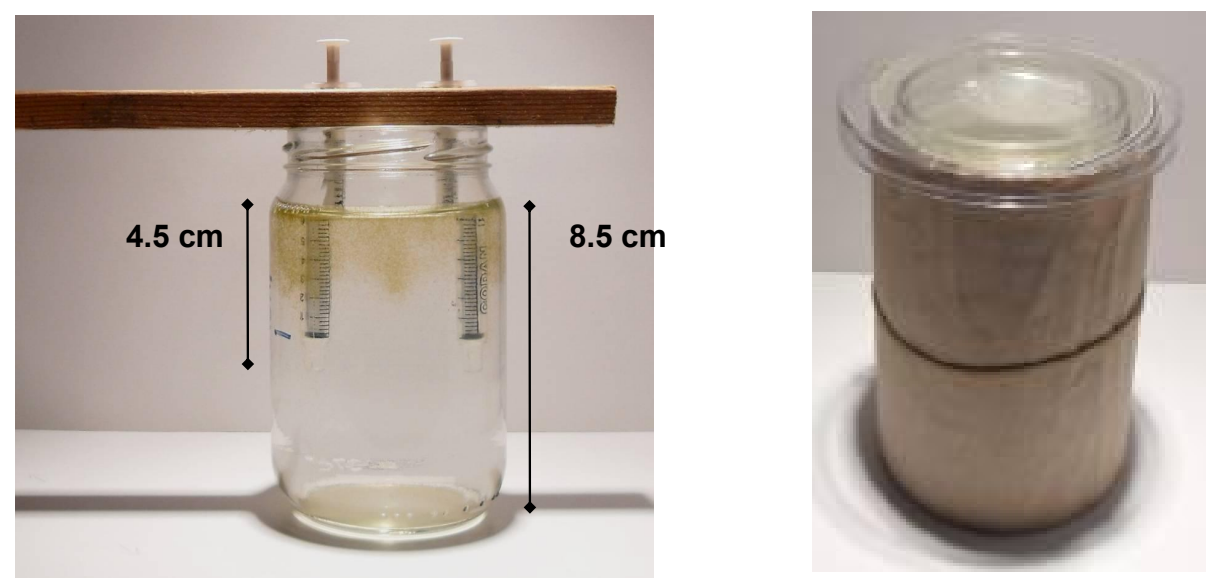

Fig. S1. Experimental apparatus for quantifying phototaxis: a) cells were sampled at $4.5 \mathrm{~cm}$ below water surface by gently lowering two insulin syringes rigidly fixed into a wood frame. Both aliquots were pooled in a test tube, fixed with Lugol and counted. b) after gentle stirring with a glass rod, the flask was covered with flexible cardboard and a polystyrene Petri dish half. Cells were only allowed to receive light vertically.

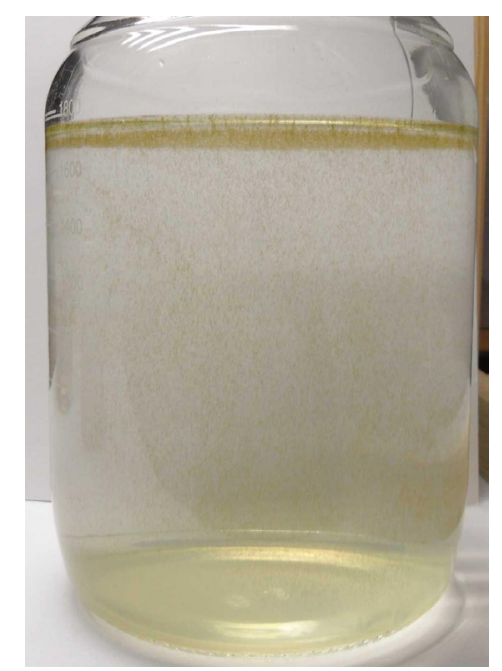

Fig. S2. G. catenatum culture in $\mathrm{f} / 2+$ Se medium grown undera cool - white fluorescent light placed horizontally above the flasks. Cells were distributed along the water column, and were not concentrated at the first millimeters below the surface. 
a)

b)
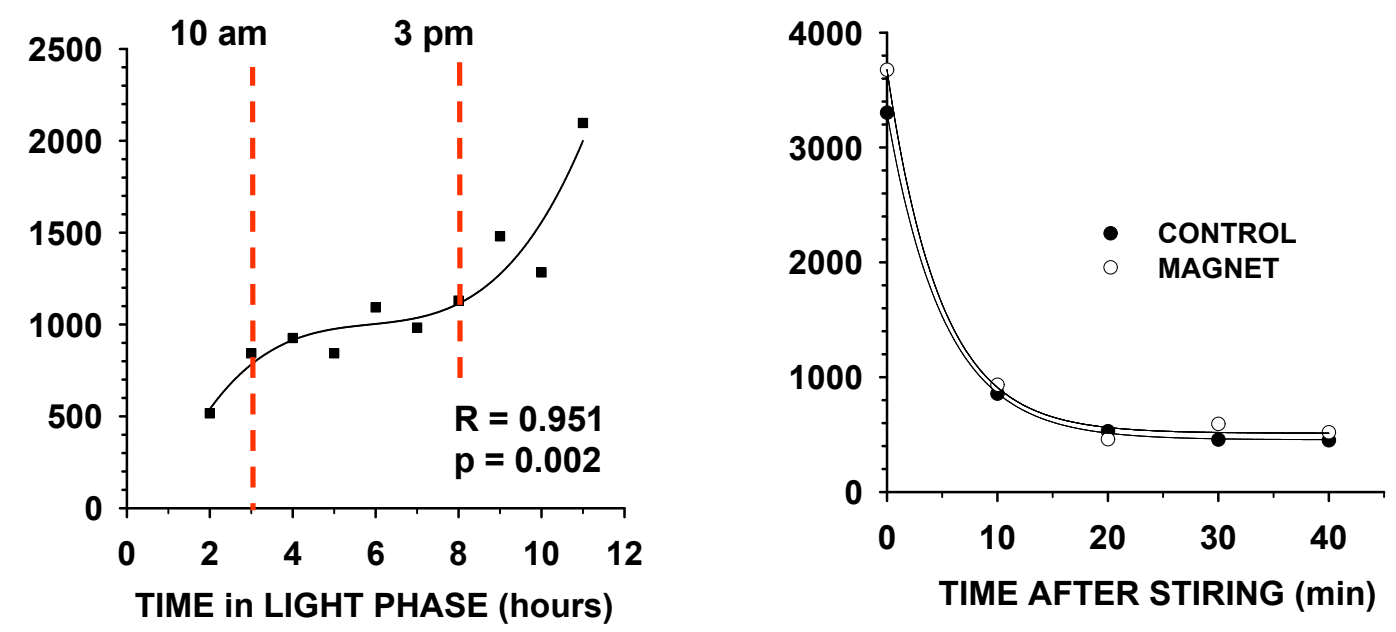

Fig. S3. a) Typical G. catenatum circadian concentration at mid-depth in an uncovered flask receiving vertical light as well as stray light during working hours (9:00 am until 6:00 pm), without any prior homogenization. Total cell concentration after homogenization and 11 hours in the light phase (or 6:00 pm) was 4000 cells $/ \mathrm{ml}$. b) cell concentration at mid-depth after an homogenization step carried out at circa 3 hours in the light phase at $22.5^{\circ} \mathrm{C}$.

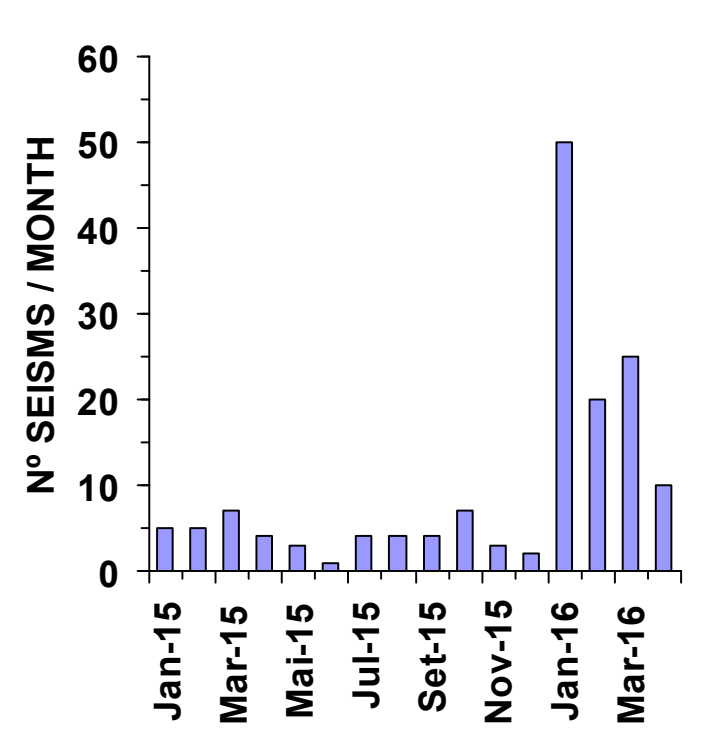

a)

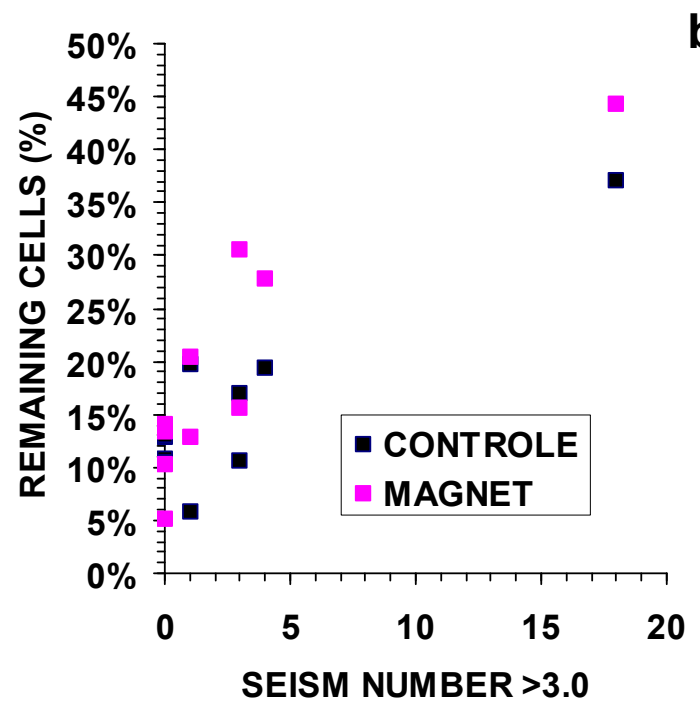

Fig. S4. a) Number of seism occurring near continental Portugal with magnitude above 3.0 on the Richter scale during 2015 and 2016. b) Correlation of the percentage of G. catenatum cells remaining at mid depth 20 min after provoked phototaxis and number of seism occurring during the 12 hours prior to the experiment (10 pm until 10 am with magnitude $>3.0$. 
CONTROL

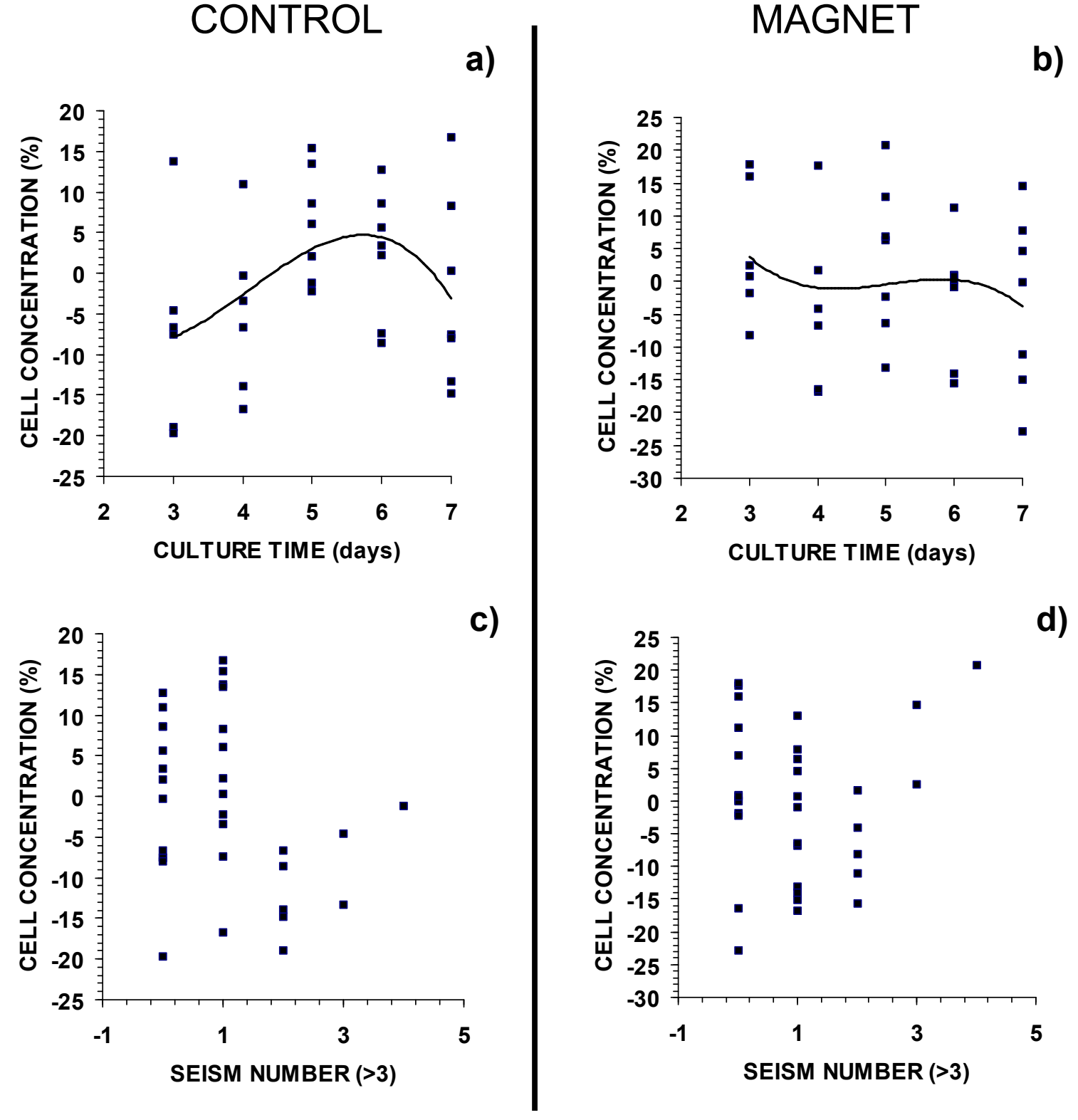

Fig. S5. Correlation between changes in cell concentration 8 hours (T8) after experiment started regarding: - culture time after last media replenishment [a) and b)]; - seism number [c) and d)].

$\mathrm{N}=33$ in all datasets. 


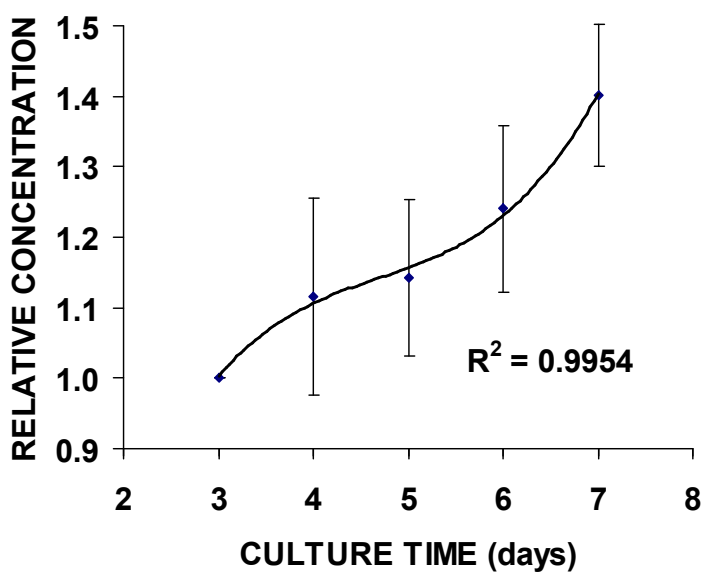

Fig. S6. Evolution of cell concentration in the inoculate at T0 relative to day 3 (Mondays). Pooled dat a f rom hypo-osmotic shock experiments run between February and March 2016 was used. 